\title{
Stakeholder perceptions about sustainability governance in the German biogas sector
}

\author{
Thomas Horschig ${ }^{1}$, Kay Schaubach ${ }^{1}$, Catharina Sutor ${ }^{1}$ and Daniela Thrän ${ }^{1,2^{*}}$
}

\begin{abstract}
Background: Since the steady growth of the German biogas sector, its sustainability is subject to constant scrutiny, especially economic and environmental sustainability. Public concerns about sustainability of biogas started with the issue of energy crop cultivation in the 2010s. To steer sustainability in the biogas sector, a broad variety of regulations and acts were enacted, mainly via top-down legislation making. But in order to govern sustainability in every step of the value chain, involvement of numerous stakeholders in the biogas sector is necessary. This paper will address the question: What are the perceptions of the relevant stakeholders in the biogas sector regarding various sustainability issues and what are their expectations?
\end{abstract}

Methods: Following an instrumental approach, three steps were initially undertaken for the systematic analysis of the stakeholder landscape, namely (1) stakeholder identification, (2) stakeholder categorization, and (3) investigation of stakeholder relationships. In addition, a theoretical mapping was performed to identify those actors, who most likely impact the implementation of biogas value chains, or are strongly affected by this implementation. These were then subject to surveys via questionnaires and semi-structured interviews to gather information on their sustainability governance perception.

Results: Results indicate that key players are farmers and biogas associations due to anchoring in agricultural sector, along with environmental non-governmental organizations (NGOs) and policy makers. Furthermore, the surveyed stakeholders agree on regulating sustainability at national level, while tending toward neutral or even disagreeing for the regulation of sustainability at local and international level. They also agree that certification and standards can be an effective tool for compliant sustainability governance.

Conclusions: This study revealed a clear expectation gap regarding the transfer of the current energy legislation in a bio-economy and how sustainability shall be steered then (mandatory/voluntary and local (national) level/international level). The surveyed stakeholders expect transparent and clear rules from the government to steer sustainability that they currently do not perceive with regard to the expectation gap. In order to integrate the different stakeholders in the bio-economy development instead of confronting them with opaque legislation making, it is important to clearly communicate not only the opportunities but also the requirements that come along with the implementation of a bio-economy.

Keywords: Sustainability, Governance, Biogas supply chain, Stakeholders

*Correspondence: daniela.thraen@dbfz.de

1 Deutsches Biomasseforschungszentrum (DBFZ), Torgauer Straße 116, 04347 Leipzig, Germany

Full list of author information is available at the end of the article

\section{Background Introduction}

To reduce the negative impact of climate change and to fulfill the goals of the Paris Agreement, Germany's government has passed the Climate Action Plan in 2016. The Climate Action Plan defines sectoral maximum

(C) The Author(s) 2020. This article is licensed under a Creative Commons Attribution 4.0 International License, which permits use, sharing, adaptation, distribution and reproduction in any medium or format, as long as you give appropriate credit to the original author(s) and the source, provide a link to the Creative Commons licence, and indicate if changes were made. The images or other third party material in this article are included in the article's Creative Commons licence, unless indicated otherwise in a credit line to the material. If material is not included in the article's Creative Commons licence and your intended use is not permitted by statutory regulation or exceeds the permitted use, you will need to obtain permission directly from the copyright holder. To view a copy of this licence, visit http://creativecommons.org/licenses/by/4.0/. The Creative Commons Public Domain Dedication waiver (http://creativecommons.org/publicdomain/zero/1.0/) applies to the data made available in this article, unless otherwise stated in a credit line to the data. 
greenhouse gas (GHG) emissions; in the energy sector, the GHG emissions have to be reduced by $61-62 \%$ by 2030 compared to the reference year 1990 [1] The biogas sector in Germany as part of the strategy has grown steadily since the enactment of the Renewable Energy Act (REA) in 2000. In 2016, it accounted for about $21 \%$ of the electricity production from renewables (including sewage gas, landfill gas and gas from the biogenic fraction of waste), constituting the third pillar of renewable electricity together with wind (42\%) and solar power (20\%) [2]. Currently, more than 9,000 biogas plants are in operation in Germany, being the largest market worldwide with an installed capacity of about $4000 \mathrm{MW}$ [3]

In Germany, biogas plants are typically organized in a value chain like the one shown in Fig. 1. Besides agricultural biogas plants representing an overwhelming share (90.7\% in 2015) [4], biogas plants processing municipal waste and organic waste are in operation, too. One unique selling point of the German biogas sector is the overwhelming use of energy crops for energy production. Due to the specific design of the most important governmental support program, the REA, and especially from 2004 on as a result of the implementation of a premium for the use of renewable resources, the input of energy crops grew steadily. This development decreased with the introduction of a maize cap in 2012. Associated research investigating this issue in more detail is published alongside with this study [5]. In agricultural biogas plants, farmers organize the feedstock supply and in most cases the biogas plant operation as well. Consequently, the farmer does not need to spend money for feedstock supply and can in turn receive income from selling digestion residues as fertilizer. In addition, single farmers or farmer consortia usually organize investment. The produced biogas is converted to electricity and heat in combined heat and power (CHP) plants. A small share of biogas plants (about 200) upgrade their biogas to biomethane, which is then used in CHP plants. Furthermore, biomethane can be used as a fuel. In contrast to other countries, the German biogas market can therefore be described as mature, being close to consolidation.

Currently, energy-related input to biogas plants is split to energy crops (76.7\%), animal excrements (14.8\%), municipal biowaste (4.6\%) and general residues and waste (3.9\%) [see 4] The input class of energy crops again is dominated by maize silage (72\%) and grass silage $(12 \%)$ with varying shares depending on the plant size (small plants use more manure, large plants use more energy crops) [see 4]. One can say that this is a highly specific situation in Germany. Production of biogas (and

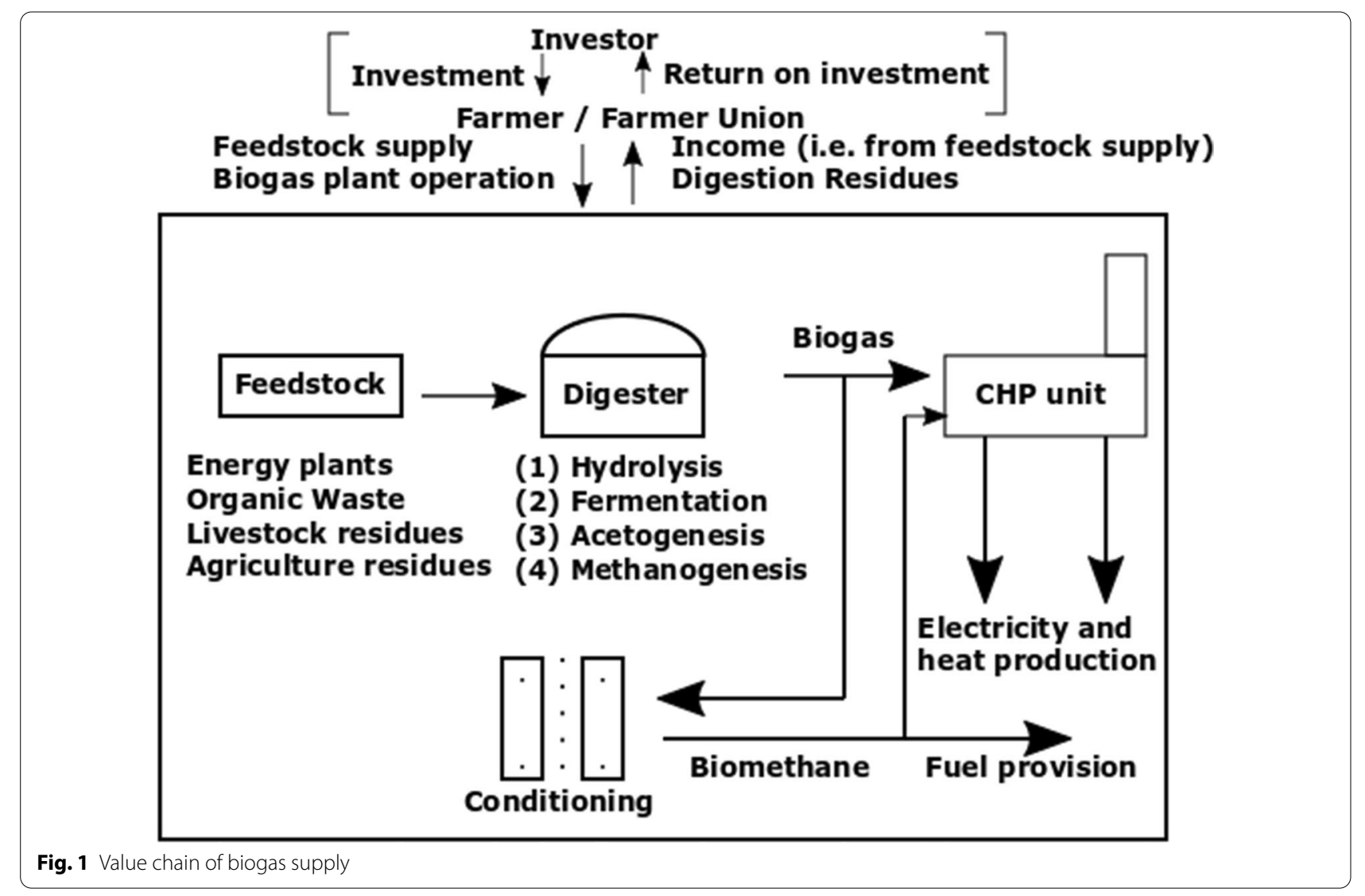


biomethane) differs largely across Europe, both in terms of production capacity per country and feedstock processed. An overview on the current situation of biogas in Europe and perspectives is given by Scarlat [6]. The status of biomethane in Europe has recently been published by Horschig et al. [7].

The production and utilization of biogas in Europe and thus in each country are governed by a variety of frameworks, either as part of a sector (i.e., agricultural sector) or for biogas specifically. The same applies for the issue of sustainability of biogas production and utilization. The sustainability of bioenergy and biogas in particular is subject to constant scrutiny, especially in the fields of economic and environmental sustainability [3, 8-10]. Here, the specific aspects of GHG emissions and crop rotation in conjunction with air quality, soil quality and water quality form the subject of investigation [11]. A part of the sustainability puzzle is the involvement of associated stakeholders. However, their role in biogas value chains and their involvement in sustainability governance have poorly been described so far. In order to develop strategies for the sustainable use of biomass, it is of significant importance to have a clear understanding of stakeholder perceptions, both regarding their general role in the value chain and their expectations of sustainability governance. Due to a lack of research in this area, and for the national case of Germany in particular, the research presented here was conducted. Consequently, this paper will take a closer look at the perceptions of these various stakeholders at different stages of production and consumption of biogas, in order to improve their involvement and nurture an effective future development. The main research question is: What are the perceptions of the relevant stakeholders in the biogas sector regarding various sustainability issues and what are their expectations? To answer this question, the relevant stakeholders need to be identified and their perceptions and expectations analyzed (Additional file 1).

\section{Theoretical framework}

Discussion on sustainability not only takes place in the scientific area but also in public, mainly via media. Public concerns about the sustainability of biogas started with the issue of energy crop cultivation for biogas production in the 2010s. The so-called maizification (increased cultivation of maize for biogas production) of Germany's landscape, along with the above-mentioned sustainability issues, has raised concerns and pushed politicians to favor waste and residues as a feedstock for biogas production. A study by Herbes et al. [12] investigated the effect of public opinion formation to policy making. In their study, they show which storyline dominated in the process of policy making with the result that maizification and food or fuel debates dominated before the REA 2012 version leading to the maize cap in the 2012 REA. This result is positioned in line with results from another study of Herbes et al. [13]. Here, they carried out a survey on the perception of renewable electricity carriers [13]. Their results indicate that biogas is the least desirable form of renewable electricity according to the surveys. The surveyed population justified their position by global advantages and disadvantages rather than local effects. The global food security is seen as more important than local noise and odor pollution. It can be stated that problems with the perception of biogas started with the cultivation of energy crops and an increased discussion about this, leading to sustainability governance. The perception of resource provision plays a crucial role. However, misguided discussions as they are sometimes observable in the media can lead to prejudices [13].

As shown above, the various sustainability aspects in biogas value chains are discussed controversially. When taking a closer look at the entire value chain of biogas production and consumption, one can identify numerous potential sustainability threats. Sustainability itself can have a large variety of meanings [14]. Within this study, we refer to the three-pillar imagination of sustainability for the definition of its concept, which means that a process can be seen sustainable when not causing irreversible changes to the environment, being economically viable and providing societal benefits [15].

In order to govern the sustainability in every step of the value chain, involvement of numerous stakeholders in the biogas sector is necessary. Participatory approaches have proven to be able to highlight different views regarding one issue and initiating learning while being often timeconsuming [16]. A recent study by Bourdin et al. [17] underlines the need for coordination between the different stakeholders to bring a biogas project to success, while highlighting also the need for regional studies. As a result, a case study of the current largest biogas market would add valuable information to both research and stakeholders in the biogas value chain.

The involvement of stakeholders into science is an expanding trend in an increasing number of research areas, like, i.e., the energy transition [18]. According to Mielke, the main aim incorporating stakeholders in fields such as sustainability science and decision-making science is to tackle the complexity, uncertainty and multiplicity. This will enable the inclusion of essential knowledge from all relevant participants. Those socalled science-based stakeholder dialogues are usually set up for the assessment of knowledge production and knowledge validity or the development and implementation of methods and participatory tools [19]. Academic literature describes a broad variety of research fields 
associated with stakeholder involvement. With respect to the field of energy transition, most of the literature relates to climate change actions or environmental governance [20, 21]. In their work, Mielke et al. [18] propose a typology for stakeholders in energy transition research in order to develop research strategies. However, this study will address a more narrow aim in a specific field of energy transition, namely biogas markets and value chains, respectively. Whereas there is a large amount of research taking place relating to biogas value chains such as anaerobic digestion technologies, feedstock supply and environmental effects, only little attention has been paid to the people involved in this value chain. Stakeholders within the biogas value chain have been used to improve findings of LCA studies due to their local character [22], supported research on investment decisions of farmers [23] and were part of model development and validation in order to increase model quality [24].

The concept of stakeholder was first defined by Freeman [25] from a business perspective as "any group or individual who can affect or is affected by the achievement of the organization's objectives." The concept has been adopted for other sectors, such as policy. Whereas the methodology for stakeholder analysis already exists, it has not yet been applied to the biogas sector [26, 27]. The perception of sustainability is analyzed in its effects on the decision making of the stakeholders. This paper does not scrutinize the perception forming processes and the respective stakeholders, which might be the subject of a subsequent study. Given this background, this paper analyzes the perception of the sustainability of biogas through the various stakeholders in Germany as a key element to be considered for a sustainable implementation of biogas routes. The results will support to "work more effectively with stakeholders, facilitate transparent implementation of decisions or objectives, understand the policy context, and assess the feasibility of future policy options" as has already been formulated by Reed et al. [26].

\section{Methodology}

\section{Scope and frame of the analysis}

Following the instrumental approach described by Reed et al. [26] as a rationale for conducting the stakeholder analysis, the study seeks to rally support for the predetermined goal of improving understanding and perception of sustainability in the biogas sector and consequently to enhance its governance. Three steps were initially undertaken for the systematic analysis of the stakeholder landscape:

(1) Stakeholder identification,

(2) Stakeholder categorization, and
(3) Investigation of stakeholder relationships.

A theoretical mapping was performed according to step 1 . This mapping was used to identify those actors, who most likely impact the implementation of biogas value chains, or are strongly affected by this implementation. These were then subjected to surveys via questionnaires and semi-structured interviews.

\section{Stakeholder description \\ Stakeholder identification}

To identify the stakeholders involved in or directly affected by policy making in the biogas sector, a qualitative literature review was completed. It was focusing on sustainability governance on social, economic and environmental level and considered articles from research and academia, as well as the specialized press. Two different types of stakeholders have to be discerned here: stakeholders for the successful implementation of the biogas value chain in general and stakeholders explicitly for sustainability issues. Based on the literature research, which was performed using ScienceDirect, SpringerLink and Google Scholar, more than 150 specific organizations and individuals, other than biogas plant operators, have been identified along and outside of the biogas value chain. These actors encompass other businesses involved with the value chain, various economic, social or environmental interest groups, and academia and policy makers.

These findings were complemented by a question in the first survey (see 2.3), asking the participants to identify institutions that they consider as important for sustainability governance in the biogas sector.

Other sources for the review included:

- Overview of companies on the website of the German biogas association (http://www.biogas.org)

- Overview of bioenergy villages on the website of the Agency for renewable resources (FNR: https://bioen ergiedorf.fnr.de/)

- Specialized press:

o TopAgrar (German magazine, print and digital, for agricultural topics)

o Biogas Journal (journal by the German biogas association)

- Local press:

o Media broadcasts from various German regions, such as "Bavarian broadcast" (BR)

- Keyword research: "Bauernverband" (local farmers associations), "Landwirtschaftskammer" (local 
chamber of agriculture), "Verband Biogas/ Bioenergie" (associations dealing with biogas or bioenergy)

\section{Stakeholder categorization}

Following Reed et al. [26], the core of the categorization is a matrix with two dimensions: Interest and Influence. Four groups can be differentiated accordingly:

(1) Key players: high interest, high influence; biggest supporters or barriers

(2) Context setters: low interest, high influence; potential supporters or barriers, have to be activated

(3) Subjects: high interest, low influence; empowerment can be considered

(4) Crowd: no interest, no influence; left unconsidered but under surveillance in case of changes; not stakeholders as such

By forming clusters of those previously identified players and assessing each player's level of interest and influence via official statements and the assessment of closely linked stakeholders, the actors were put in the matrix, categorizing them in the four distinct fields.

In addition, the stakeholder groups have been evaluated regarding their supportiveness or unsupportiveness of large-scale biogas deployment (and ensuing energy crop cultivation), opening a scale between opponents (against large-scale biogas plants associated with energy crop cultivation) and supporters. The information has been gathered through literature review, surveys and interviews. Unclear cases were treated as "neutral." The results have been transferred to the value chain-based maps, color-coding the stakeholders' different positions. Opponents are marked in red, supporters in green and neutral or indifferent stakeholders in orange. This forms the basis to devise ways and strategies on how to engage them henceforth.

\section{Relationships of stakeholders in the biogas sector}

Based on Reed et al. [26], the method of actor linkage has been chosen to indicate links between the actors by the categories conflict, complement or cooperation. The interviews with key stakeholders provided the results for this matrix and only the most important stakeholders with the strongest links are displayed.

\section{Analysis of sustainability perception through questionnaires and interviews}

The analysis consolidates ideas, concerns and perceptions of the stakeholders in regard to sustainability governance. The analysis also helps in discerning which conflicts exist between stakeholder groups and how to tackle them effectively. Even if this does not lead to a modification in the stakeholder's viewpoints, it can facilitate a closer collaboration and more acceptance of the counterpart's opinion.

\section{Design of the questionnaire and interviews}

In general, the questionnaire and interviews were designed to gain an understanding of both the prevailing perceptions of the stakeholders regarding sustainability and governance, in order to locate possible areas of divergence where intervention is possible, as well as to observe how the stakeholders perceive their status in the sustainability sphere of the sector. The combination of questionnaire and interviews was chosen to gain a broad understanding of the sector's stakeholders' mood and to be able to reinforce this with details from selected individuals' views.

The questionnaire has been developed by the International Energy Agency (IEA) [28] working group as part of a project surveying different countries (USA, Canada and Germany), with different bioenergy sources and a large variety of stakeholders. It has therefore been held rather general for comparability and was only slightly adapted for the German biogas sector, not addressing the very specific challenges the sector faces. Ten statements were posed and then meant to be answered on a scale between "fully agree" (1st score) to "fully disagree" (5th score).

The interview questions took this survey as basis and asked in eight to twelve queries for certain aspects more in-depth, to support, clarify or add to the surveyed statements as well as to address the more specific German challenges of the issue.

\section{Application of the questionnaire and interviews}

In the first round, a paper-based version of the questionnaire has been sent out to 743 biogas plant operators in March 2017, which represent $8 \%$ of all biogas plant operators in Germany. 114 responses were received (group A). Next, an online questionnaire with the same questions has been distributed in November 2017 to reach further stakeholders from the domains society, economy, academia and politics; out of 150 recipients, 27 responses were received (group B). Actors were chosen either to cover the entirety of the biogas value chain or as outside parties directly involved in biogas deployment or its governance. Figure 2 shows the stakeholders' various institutional backgrounds from the second survey round.

Lastly, in March 2018, ten telephone interviews were held with a sample of survey participants from groups $\mathrm{A}$ and $\mathrm{B}$, again covering important actors along the value chain and outside of it to compare different perceptions. The interviews were held anonymously, so the respective stakeholder will only be identified by 


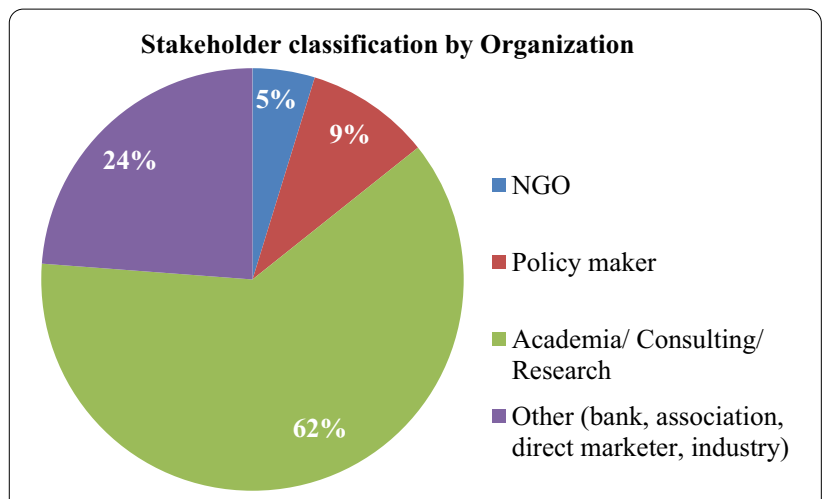

Fig. 2 Stakeholders' institutional background from online survey

their general institution or occupation, which included two NGOs, two businesses, three plant operators, one governing institution, one association and one academic researcher. Each interview was held by two researchers (one interviewer and one recorder) and took about $60 \mathrm{~min}$. They were structured similarly to the questionnaire, asking for more detailed perceptions on and attitudes toward sustainability and governance in the biogas sector. The replies from the interviews were grouped in a qualitative way.

\section{Results}

\section{Analysis of stakeholder landscape}

The stakeholder landscape proved diverse in the preliminary literature examination. Being the most important link of the value chain, biogas plant operators formed the first group of stakeholders under investigation. Next, a systematic review of the value chain exposed further stakeholders, namely farmers, plant constructors, investment banks, logistics and service firms, and utilities. Outside the value chain, there are the various interest groups, both associations for the promotion of biogas deployment (e.g., national and local farmers and bioenergy associations), and those opposing large-scale deployment (e.g., environmental activism groups, citizens' initiatives). Moreover, national and state policy makers dominate the discussion, as they set the framework for sustainability governance measures and ideally must balance the interests of various groups while maintaining sustainability on all levels. Regional and national media outlets and research facilities were additionally identified as stakeholders, as they can largely influence opinions and perceptions through their reports and studies. The feedback in the questionnaire reflected stakeholders who were already put on the list. The Association for Biogas (Fachverband Biogas) and Chambers of Agriculture were named by 29 respondents in the first survey.

Next, the identified stakeholders were clustered according to categories (Fig. 3). The category of "subjects" can be examined in groups of affected residents, meaning

\begin{tabular}{|c|c|c|c|c|c|c|c|}
\hline & SUBJECTS & & & & & & KEY PLAYERS \\
\hline & & Citizen & itiative & Plant o & & Farmers \& biogas & sociations \\
\hline & & Organi & rmers & Conventic & mers & & \\
\hline & & & Bioene & gy village & & Environmental NGOs & \\
\hline & & Service & oviders & .g. $\mathrm{M} \& \mathrm{O})$ & & & Policy makers \\
\hline$\uparrow$ & Affecte & esidents & & & & & \\
\hline 5 & & & & & & & Academia \\
\hline 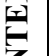 & & & & & & & Media \\
\hline & & Investm & banks & & & & \\
\hline & Public & & & & & & \\
\hline & CROWD & & & & & & CONTEXT SETTERS \\
\hline & & & & & UEN & WER $\rightarrow$ & \\
\hline & unsu] & rtive & sup & ortive & neuts & ecisive & \\
\hline
\end{tabular}


those who have a biogas plant within their community. This can either be the result of a decision made on community level (as in bioenergy villages) [29], which usually harbors great support from the affected citizens, or unilaterally by one or more farmers or other actor(s) who invested in a plant, which can in some cases lead to the formation of citizens' initiatives opposing the construction of the plant (as in the initiative "Biogasanlagen versus Anwohner": (https://biogasanlagen-versus-anwohner. $\mathrm{de} /$ ) [30]. In addition, commercial enterprises, such as for the construction of plants, their maintenance or other service providers, hold an interest in the topic as their profit depends on decisions made about the sector on political level. Farmers, both conventional and organic, can be viewed as key subjects, as they are affected on multiple levels, because they are dependent on the market prices of feedstock, land lease prices, fertilizer regulations and many more, all topics which are important to the biogas and sustainability debate. Usually, while having interest in the issue and opinions swaying in all directions, those groups (at least when unorganized) have little influence in affecting or changing decisions.

The "context setters" are the media and academia. They can sway opinions based on their reports and analyses while appearing neutral in their own opinion. They usually set the mood for the issue at hand. These and the key players were additionally identified and confirmed by the interviewees, being asked who they view as having the biggest influence in the debate.

The "key players" are the most important stakeholders to be considered as they can control outcomes. Policy makers, on European, national and state level, for example ministries for agriculture, set the framework of governance. What this governance contains, though, is largely influenced by powerful interest groups on all levels of supportiveness. Biogas or farmers associations represent the industry and thus will lobby policy makers to create regulations in their favor. On the opposing side, (environmental) NGOs exert pressure for stricter sustainability regulations. They are unsupportive not of use of bioenergy in Germany, but the development of the sector toward large energy crop use and perceived loss of biodiversity. The interviewed environmental NGO stated: "focus should be shifted toward increased use of waste material."

The "Crowd" are not stakeholders in the conventional sense, as they usually do not hold a stake in the issue. In this case, the general public can be viewed as crowd, as they might follow sustainability debates in the media, yet do not take action in its governance. Similarly, investment bank and utilities can be put in this field, as their interests lie in different areas than the one under scrutiny. The following figure presents the most important stakeholders within the interest-influence matrix, colorcoded to indicate support (green), opposition (red) and neutrality (orange) of large-scale biogas deployment.

The relationships between the stakeholders can be traced along the lines of level supportiveness, displayed in Fig. 4. Actors that are supportive of large-scale biogas deployment form a collaborative or complementary bond, such as farmers, biogas plant operators and farmers associations. Correspondingly, actors with differing views, such as environmental NGOs or citizens' initiatives versus farmers associations and plant operators, are in a conflicting relationship, confirmed during interviews with actors on both sides. Interestingly, the most volatile relationships are those between neutral stakeholders and others, as their interrelation is prone to changes. Depending on current viewpoints (usually strongly influenced by the media), attitudes and relationships shift, as for example local residents pick up arguments against biogas plants and then start a conflicting relationship with the local biogas plant operator.

Moreover, the survey and interviews revealed that biogas plant operators feel unheard from policy makers and misunderstood from the general public, indicating that there is a need for better communication between those players. Negative depiction in the popular press turned the tide against biogas, creating more conflicting relationships and dissonance between actors. During the interviews, farmers and plant operators presented themselves as adverse toward environmental NGOs and vice versa. Policy makers are generally viewed (by almost all other stakeholders) as not comprehending the issues, putting too little emphasis on scientific facts and therefore not governing sensibly.

Facilitating conversation and understanding between those actors is thus imperative for an effective stakeholder dialogue and balanced governance decisions.

\section{Sustainability perception}

While the first questionnaire was exclusively sent to plant operators, the second, online one, was made up of various stakeholders, consisting mostly of actors from research/academia, policy makers, businesses, associations and NGOs. When it comes to the assessment of current sustainability governance, the answers in the online survey (group B-grey) were more differentiated, yet show a similar trend to the survey of plant operators (group A-green), shown in Fig. 5. In both surveys, participants agreed that sustainability requirements should be mandatory for all biomass types regardless of end use, while group B respondents agreed even more strongly with this statement. They also disagreed more strongly with the statement that current sustainability certification schemes/ systems for bioenergy are 


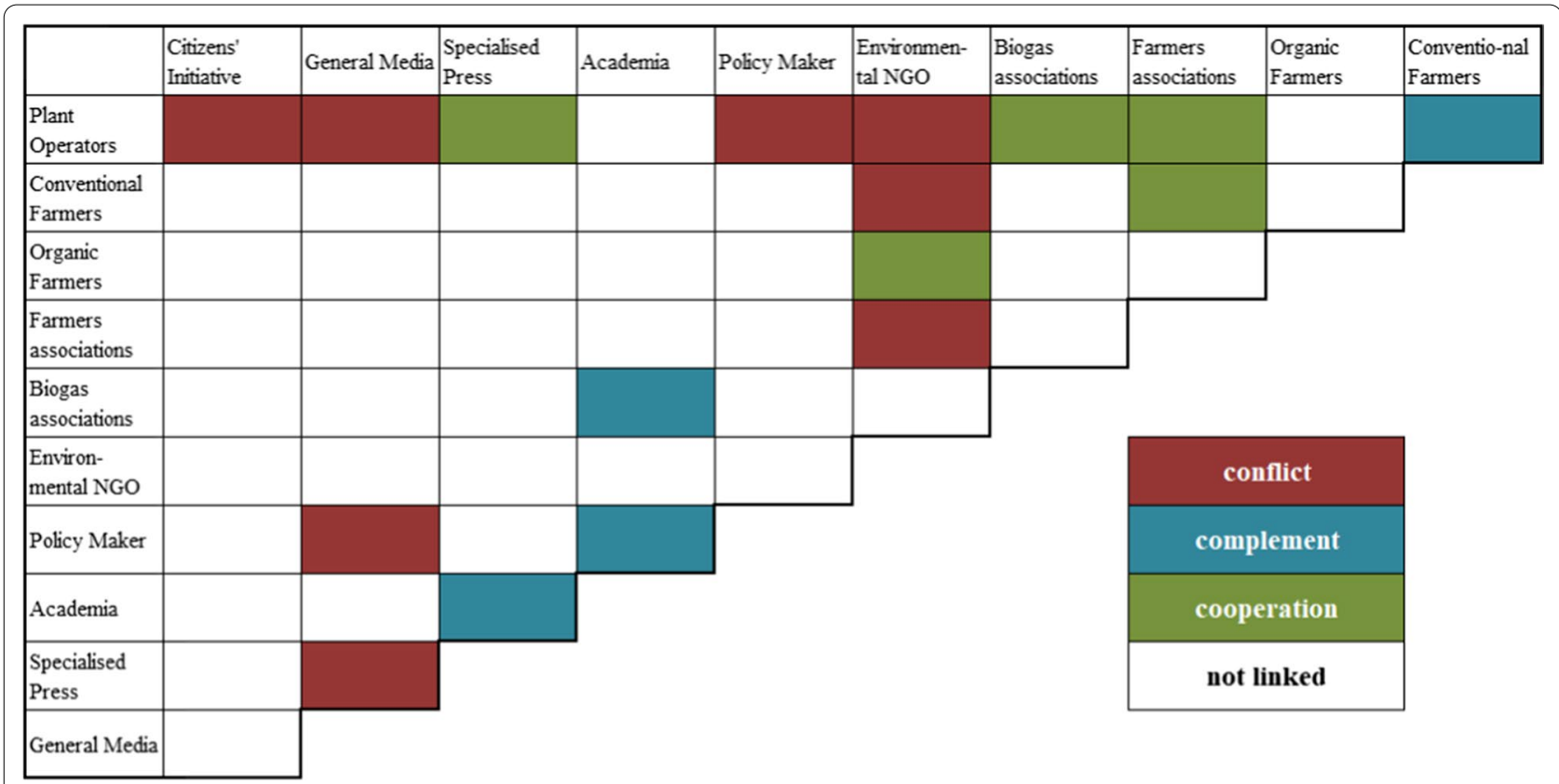

Fig. 4 Actor linkage matrix of stakeholders

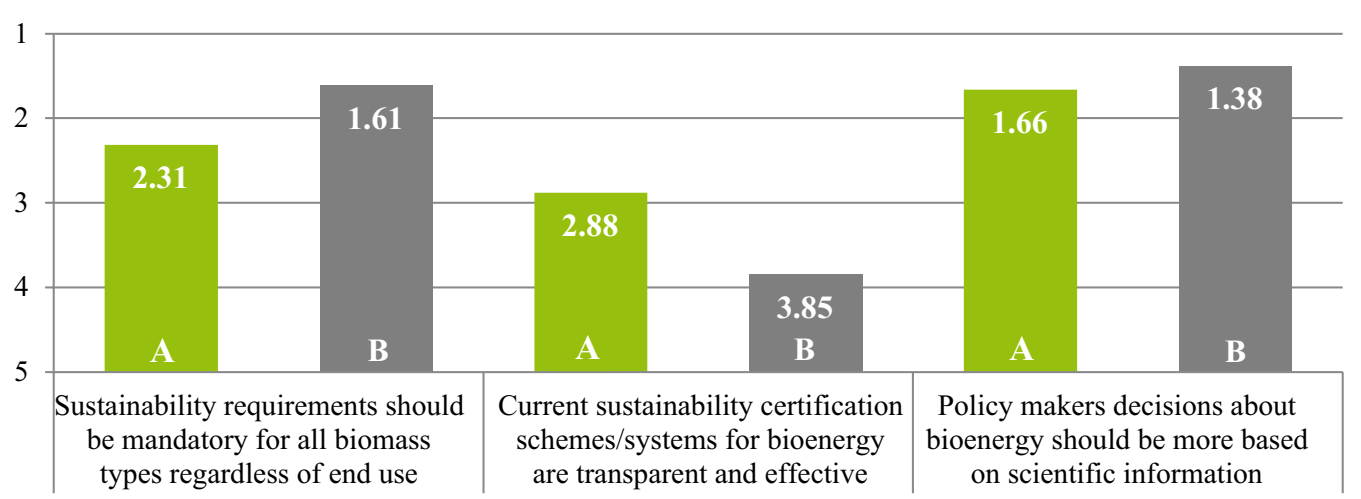

Fig. 5 Perception of sustainability governance (a plant operators; b various stakeholders. Scale: 1—fully agree, 2-agree, 3—neutral, 4-disagree, 5-fully disagree)

transparent and effective, while group A took a more neutral to slightly agreeing stance here. Stakeholders outside the production chain can hence be viewed as more demanding when it comes to imposed requirements on sustainability. Both groups did agree rather strongly that policy makers should base their decisions more on scientific information, leading to the assumption that all stakeholders still trust in scientific research and would like to see their findings implemented in policies, rather than calming critical (emotionally charged) voices of the general public through changed regulations.
Next, deciding on which level bioenergy should be governed, the highest consensus was built for regulating it at national level, while tending toward neutral or even disagreeing for the local and international level (Fig. 6). This conforms to the current legal framework where laws are enacted on federal level, often adapted on the basis of European directives.

Furthermore, regarding compliance with sustainability standards, biogas operators (group A) would preferably see a system of voluntary compliance (such as in the "best practices for agriculture"-"gute fachliche Praxis") and do not agree that it should be mandatory, fearing 


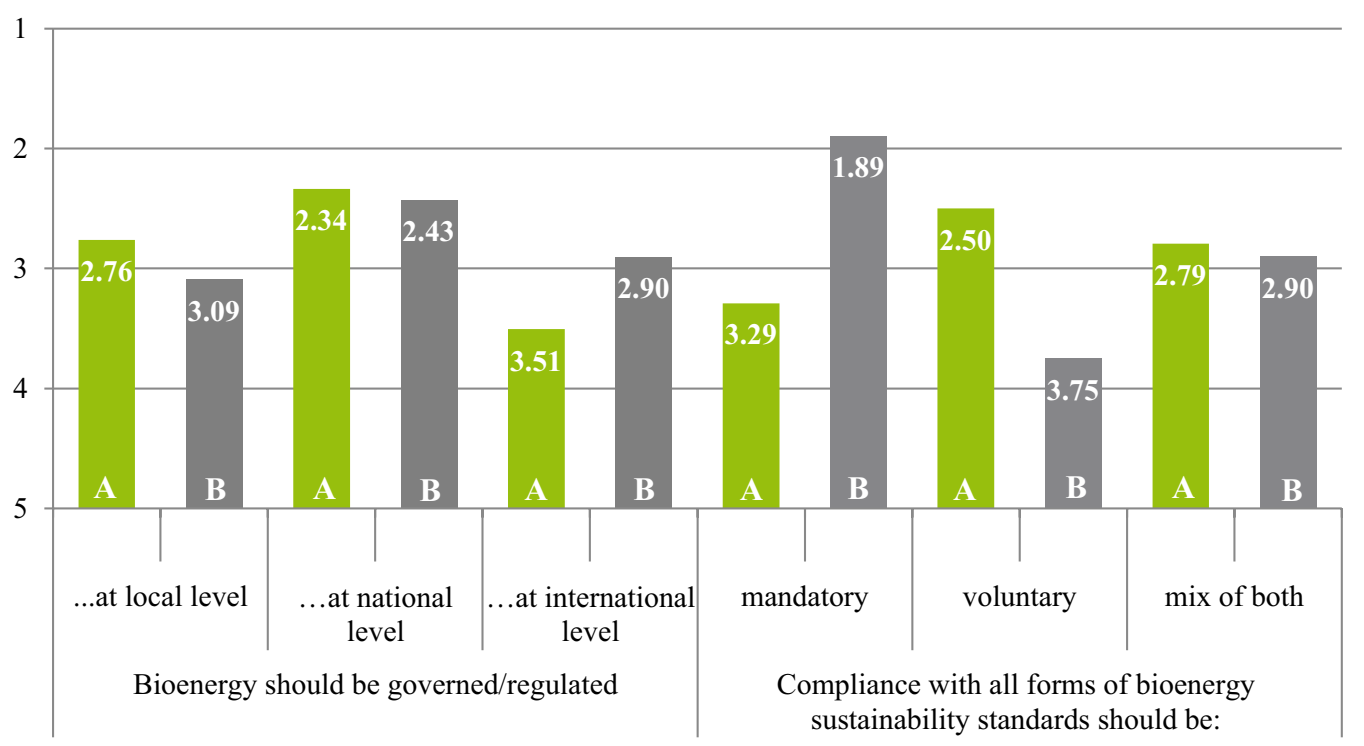

Fig. 6 Level of governance and compliance (a plant operators; b various stakeholders. Scale: 1—fully agree, 2-agree, 3—neutral, 4-disagree, 5fully disagree)

mounting regulations and restrictions. Quite the reverse is the case for the various stakeholder groups (group B), as they agree quite strongly with mandatory compliance and reject the idea of voluntary conformity. For biogas plant operators, complying with sustainability standards, adds burdens in the general management of their business, as they see increasing demands without concurrent increasing compensation. Contrastingly, outsiders see sustainability compliance as essential and obligatory, thus taking the (easier) role of demand maker, not realizing the hardships this entails for plant operators and farmers.

The participants seem to be unsure how to reply to the next statement on models of supply chain coordination, landing within the range of neutral for all three suggestions (Fig. 7). Particularly, the biogas plant operators (Group A) seems to not prefer any of the given options, namely manufacturer-led coordination (appointing one focal company as responsible to the collection of information throughout the supply chain), producer-led coordination (farmers would be responsible for information collection) or a mix of both. This could mean that either the question was not phrased comprehensibly enough for the respondents to develop a clear opinion, or that supply chain coordination in general is not an issue they are concerned with and thus have no notion of its effective implementation.

Then the participants were asked how they see the best form of verification fit, showing great divergence between groups, as biogas plant operators (group A) would prefer either self-auditing of no verification at all, disagreeing with the system in place of independent certification with third party auditing based on sustainability standards, whereas the various stakeholder participants (group B) prefer this option, disagreeing that verification is not needed. Here, plant operators fear additional costs and bureaucracy, and some other stakeholders agree: "Sustainability certifications create bureaucratic monsters (e.g., sustainability certificate for ignition oil of the plant)."

Concerning drivers of bioenergy production, both groups confirmed development of a circular economy to be the top reason, followed by reduction of greenhouse gas emissions, and energy security/ security of supply (Fig. 8). Biogas plant operators (group A) weigh those drivers with decisive agreement, confirming their role and importance in the German energy transition, as well as their function in promoting a circular economy. The various stakeholders (group B) are less sure in their decisions, coming up in a close to neutral range for all drivers.

On the other hand, major barriers for the development of the bioenergy sector were chosen to be foremost lack of scientific information for better informing policy makers $\mathcal{E}$ general public by group A and lack of economic stimulation/market incentives by group B. One can derive that the operators (group A) feel unjustified from the political side, as they are under the impression that scientific information is neglected in favor of public opinion in decision making, while the other group (group B) takes a more neutral stance on this issue, possibly finding scientific information adequate within political and public debate. Both groups identified lack of economic stimulation/ market incentives as major barrier, criticizing the 


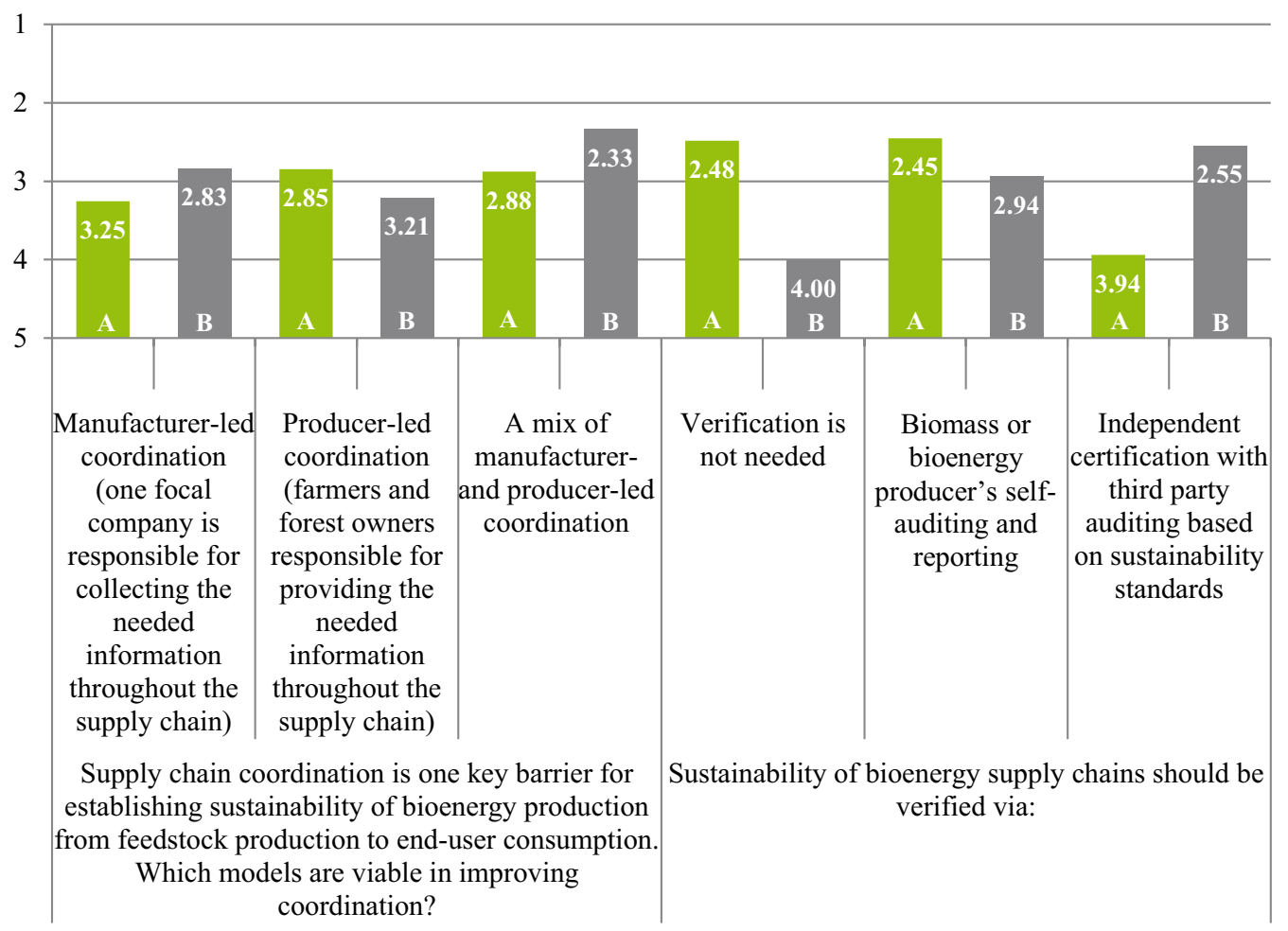

Fig. 7 Perception of sustainability verification and supply chain coordination (a plant operators; b various stakeholders. Scale: 1—fully agree, 2agree, 3-neutral, 4-disagree, 5-fully disagree)

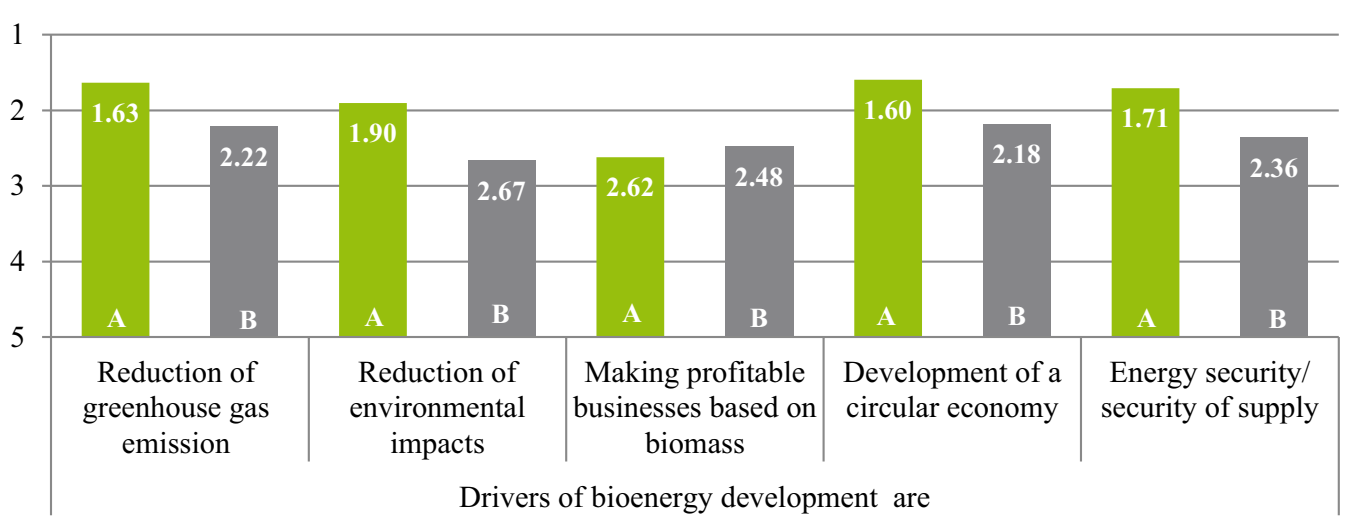

Fig. 8 Drivers of bioenergy development (a plant operators; b various stakeholders. Scale: 1—fully agree, 2—agree, 3—neutral, 4-disagree, 5— fully disagree)

economically unsustainable direction the REA has taken for biogas plants in the recent amendments.

The last query focused on a related issue, asking participants to determine how much different challenges affect bioenergy production and its supply chain (Fig. 9). Both groups decided no contribution to economic growth could not be considered a big challenge for the sector, thereby agreeing that the industry does contribute to economic growth. In both groups, lack of societal acceptance seemed to be regarded as the biggest challenge of the given possible options, an issue that has become apparent through previous statements already. On whether undesired environmental impacts cannot be avoided is a challenge, both groups leaned toward neutrality with a slight tendency to agree. This shows that they are aware of the issues caused to environmental sustainability and 


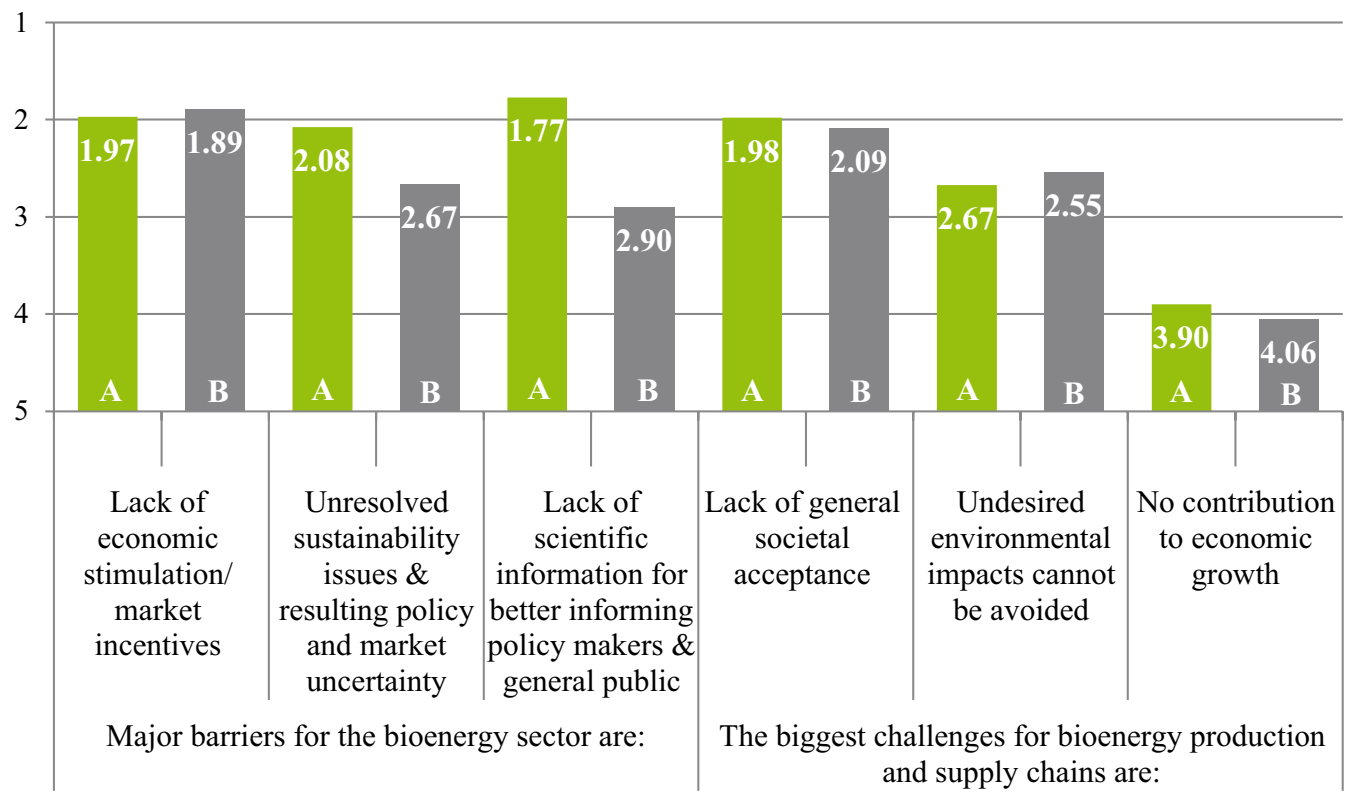

Fig. 9 Barriers and challenges (A: plant operators; B: various stakeholders. Scale: 1—fully agree, 2—agree, 3—neutral, 4-disagree, 5—fully disagree)

concede to accepting them, as not all can be averted. Comments from the group A survey mirrored frustration on the issue, including "political volatility and no legal certainty for institutions," "lack of knowledge among politicians," "depicting a true picture in the media" and an "uncertain future."

For the next step, the interviews were held with the selected stakeholders. During the interviews, attitudes toward sustainability of biogas and sustainability governance of biogas were investigated, along with perceptions of the degree of influence over sustainability governance, as well as different roles, responsibilities and goals of stakeholders. The participants came from different regions in Germany, which painted an interesting picture and highlighted regional differences and views, for example concerning maizification, which is generally a bigger problem in the North of Germany. The interviewees all consented that the sector is stagnating and its future looks uncertain. This indicates that economic sustainability is one aspect that is not given. Moreover, the interviewees condemned the extremely volatile political landscape, the disregard of the factual basis and the emotionalization of the public and political debate. Sustainability is comprehended in a similar fashion among all interviewees: foremost in the environmental sense, yet the economic sphere cannot be disregarded, especially by plant operators and businesses. When talking about other sustainability aspects, the interviewees mentioned soil sustainability, food vs. fuel debate, maizification and water pollution. Lack of communication between the general public (especially local residents) and farmers/ plant operators was identified as a major obstacle in societal acceptance, in conjunction with negative ("sensational") depiction in the media. Multiple interviewees underline the importance of cooperation between different stakeholders, such as associations and NGOs (for example in collaborative projects), in order to thwart confrontation. One key finding is that local solutions are important: due to regional differences in ecosystems, biogas sustainability must be managed accordingly and not by a "one size fits all" type of governance. Direct communication between the stakeholders fosters understanding, especially between plant operators and local residents. Local media outlets are now more important than national ones, because biogas is seldom seen in the national debate anymore, while regional reports can create a sense of connection to the biogas undertakings within the community.

\section{Common viewpoint and major differences of stakeholder groups}

Commonalities and differences in viewpoints can be easily discerned by determining the spreads between answers given to the statements by Group A and B. A spread of equal to or more than 1 indicates a major disparity of opinions between the two groups. Six statements harbor this result. Results with less than 0.5 indicate common viewpoints. Eleven answers are 
holding this result. Spreads between 0.5 and 1 are in the grey area between common and different viewpoint. Nine statements are representing this area. Most of the larger differences can be observed in statements regarding instruments of sustainability governance, which are rejected by group A and supported by group B, such as certification schemes, standards, verification. Group A values autonomy and less outside control, while group B values the opposite. Opinions converge mostly regarding drivers, barriers and challenges of the bioenergy development, finding common ground in how the status of the sector is perceived and agreeing on the importance of factual over emotional debates.

\section{Discussion}

The proposed approach of systematically establishing an overview of stakeholders, with a classification of their roles and their interrelationships proved exhaustive and holistic. While plant operators are instrumental in the implementation of the biogas value chain, they were not identified as key players, due to their lack of influence. Key players actually dominating the governance of biogas supply chains are (organized) associations for the promotion of biogas, as well as against it, and the policy makers themselves. Next, the perception of sustainability issues between plant operators and other stakeholders was contrasted. All stakeholders rated environmental aspects very high; the interviews revealed in detail the severity of the raw input material issues. Nevertheless, the perceived best way for the governance of sustainability to address these issues is viewed differently. The survey was successful in discerning the needs of plant operators, which are more freedom and less regulatory control in their business conduct, as well as more transparent procedures, science-based methods and more predictability when it comes to future developments. It also found the disparities to other stakeholders, which are most evident in the voluntary versus mandatory dispute. One study by Huttunen et al. [22] recommends the involvement of stakeholders (in this case via interviews) to better implement life cycle thinking during policy making whilst another study by Pehlken et al. [31] argues that integration and participation of stakeholders in the whole process chain is mandatory to unlock biomass potentials and improve sustainability impacts. To conclude this, one study by Sinclair et al. [32] summarizes this issue with the results they found. First, they argue that information gathered during such involvement actions like interviews aided to the development of a sustainability assessment framework. However, due to the large diversity of perceptions of different groups of stakeholders, novel approaches to problem structuring are needed [32]. Consequently, an approach such as the one presented here helps significantly to gather information and support the sustainability discussion but stresses the need for further actions like problem structuring.

The interviews were designed as part of an IEA project, which was performed in key countries of biomass production and consumption with exemplary markets (such as the project regarding biogas in Germany conducted by us). To better compare the results and thus the different markets across Europe that had been investigated, the questionnaires were designed to fit the different markets, with only small feasible regional adjustments. One could argue that the more generalized nature of the questionnaire inhibited concrete solution finding for the German sector. However, this procedure allows the different markets to be compared. The results presented here should be seen as part of a more encompassing view on governance by adding information about the national case of stakeholder perceptions regarding sustainability governance in the German biogas market [28]. This also resulted in some questions not being relatable for certain stakeholders and thus responses which did not indicate a clear opinion.

Another limiting factor in the analysis is the imbalanced and relatively small number of respondents to the second (online) questionnaire, which consisted largely of other research or academic institutions. We want to further highlight that the low amount of responses (27 out of 150) from the domains of society, economy, academia and politics represents a small sample size, and the results relating on this can be seen as individual statements rather than representative perceptions. However, some of those ambiguities and imbalances could be made clearer during the interviews, filling gaps and clarifying viewpoints in order to gain a well-rounded picture.

\section{Conclusions and policy implications}

Germany's biogas market, which is the largest worldwide, can be considered a consolidated market with a differentiated stakeholder structure (see the associated article within this special issue by Thrän et al. [5]. Because a large proportion of the biogas plants are situated within agricultural production, key players are farmers and biogas associations, along with environmental NGOs and policy makers. According to the results of this study, in some cases public initiatives and environmental initiatives can be considered unsupportive. As a main field of conflict, we identified resource mobilization in intensive agricultural production systems mainly associated with sustainability threats.

Whereas this study does not reveal the processes of sustainability perception setting, it draws a clear picture of how sustainability is perceived by a broad variety of stakeholders within the German biogas sector. In total, 
141 different stakeholders were surveyed. The results were distinguished for two groups, namely biogas plant operators (group A), and other stakeholders (group B).

Both surveyed groups agree on regulating sustainability at the national level, while tending toward neutral or even disagreeing for the local and international level. They also agree that certification and standards can be an effective tool for compliant sustainability governance. This is in line with current findings of other studies [9]. However, with regard to this study, the different stakeholder groups see it adverse, how certification and standards shall be implemented in sustainability governance. Whereas group A (biogas plant operators) does not agree that sustainability compliance should be mandatory, group B (other stakeholders than biogas plant operators) agrees strongly with this. Group A fears mainly increasing demands without concurrent increasing compensation as they are currently already obliged to be compliant with a couple of standards and premium specific certification like biomass specific input premium in the REA.

In general, conflicts within the biogas sector (farmers vs. environmental NGOs) are in some way similar to observed conflicts within the agriculture sector (Fig. 3). One approach of how to reduce conflicts between the different stakeholders is given by so-called best practice examples through reducing local conflicts by trying to implement a compromise between local perception and an economic biogas plant operation. Such a good practice example, which helped to reduce local tensions, has been the planting of other plants than energy crops for biogas production at the edge of the energy crop field to improve landscape perception of the residents. In another example, a plant operator has gained praise for planting cup plant (silphium perfoliatum, considered an alternative, yet less-productive, plant to maize) by his own initiative to promote biodiversity in his region, even just on a small fraction of his land. Even better are examples which create win-win situations for operators and residents, e.g., by heat utilization from the plant for the nearby households, or the possibility for residents to discard of their bio-waste at the plant. Fostering communication and a good relationship by means such as these has shown to increase trust and understanding between stakeholders.

Finally, both groups perceive the great opportunity that comes along with the implementation of a bioeconomy like it is favored by the German government and supported through various initiatives [33]. The questions of which are the sustainability standards and how they shall be implemented are key questions for the future legislative framework governing the sustainability of the bio-economy. Currently, sustainability and climate protection measures are not well compensated in the agriculture sector [34]. One reason for this is their exclusion from the European Emission Trading Scheme. Therefore, sustainability threats from biogas plants such as GHG emissions from missing fermentation residue covers are not depicted in the market and have to be regulated externally.

Still, both surveyed groups perceive a lack of economic stimulation/ market incentives as major barrier for this and criticize the economically unsustainable direction the REA has taken including a feeling of being unheard. These study's findings indicate that, on the one hand, stakeholders within the biogas sector as well as the government favor the development of a biobased economy but current incentives to support this are too low and too volatile, which comes along with the threat how the future will look like for biogas plant operators. A long-term perspective with transparent requirements regarding climate protection would be an asset for biogas plant operators. Biogas plants can play a key role in the future bio-economy through improving nutrient cycles, extraction of valuable substances from biogas plants, etc. The vision of a bio-economy goes far beyond pure energy provision but is currently not well defined by goals.

In sum, the results show clearly that the surveyed stakeholders expect transparent and clear rules from the government to steer sustainability. Those conclusions lead to different policy recommendations for implementing agricultural biogas systems:

- Because sustainability regulation is seen as a central issue in the stakeholder perception, implementation of related roles and governance is one of the important actions accompanying the biogas market development. The decision how those sustainability regulations are realized (mandatory or voluntary) depends on the kind and amount of feedstock used in the biogas plants: the utilization of energy crops is perceived with higher risks, so that mandatory sustainability regulations are reasonable, if the cultivation is supported on a larger scale.

- Pricing the climate gas emissions from the agriculture sector could be a relevant economic incentive and especially support efficient biogas systems.

- Additional best practice examples are important, especially to reduce local tensions; they should include a sustainable resource base but also high energy yields and/or the provision of local energy

- Biogas production should not only be seen as an element of renewable energy provision but also integrated into national bioeconomy strategies and in the transformation toward an environmentally sound agriculture 
In order to integrate the different stakeholders in the bio-economy development instead of confronting them with opaque legislation making is important to clearly communicate chances but also demands that come along with the implementation of a bio-economy. This is the distinct task of decision makers. This study revealed a clear gap regarding an expectation management of how the current energy legislation (Renewable Energy Act) should be transferred in an encompassing bio-economy. One possibility is seen in the direct utilization of waste streams from livestock production in integrated production systems using the existing biogas infrastructure in Germany, which can lead to a considerable reduction of GHG emissions in the agricultural sector. However, to further exploit this potential, this service needs to be monetarized in order to develop new business cases for biogas plant operators outside of the existing incentives, which are mainly focused on energy production.

\section{Supplementary information}

Supplementary information accompanies this paper at https://doi. org/10.1186/s13705-020-00270-5.

Additional file 1. Appendix.

\section{Abbreviations}

NGOs: Non-governmental organizations; GHG: Greenhouse gas; REA: Renewable Energy Act; MW: Megawatt; CHP: Combined heat and power; IEA: International Energy Agency.

\begin{abstract}
Acknowledgement
IEA Bioenergy, also known as the Technology Collaboration Programme (TCP) for a Programme of Research, Development and Demonstration on Bioenergy, functions within a Framework created by the International Energy Agency (IEA). The views, findings and publications of IEA Bioenergy do not necessarily represent the views or policies of the IEA Secretariat or of its individual Member countries.

The content of the paper is part of the findings of the IEA inter-task project Measuring, governing and gaining support for sustainable bioenergy supply chains which has received funding from the Technology Collaboration Programme (TCP) for a Programme of Research, Development and Demonstration on Bioenergy. More information can be found at https://www.ieabioener gy.com/task/inter-task-projects/.
\end{abstract}

\section{Authors' contributions}

All authors contributed to the development, revision and finalization of the article. All authors read and approved the final manuscript.

\section{Funding}

Open Access funding enabled and organized by Projekt DEAL. The project is supported by funds of the Federal Ministry of Food and Agriculture (BMEL) based on a decision of the Parliament of the Federal Republic of Germany via the Federal Office for Agriculture and Food (BLE) under the innovation support program. Further funding was received from the Technology Collaboration Programme (TCP) for a Programme of Research, Development and Demonstration on Bioenergy.

\section{Availability of data and materials}

The datasets supporting the conclusions of this article are included within the article.

Ethics approval and consent to participate

Not applicable.
Consent for publication

Not applicable.

\section{Competing interests}

The authors declare that they have no competing interests.

\section{Author details}

${ }^{1}$ Deutsches Biomasseforschungszentrum (DBFZ), Torgauer Straße 116, 04347 Leipzig, Germany. ${ }^{2}$ Helmholtz Centre for Environmental Research UFZ, Permoserstraße 15, 04318 Leipzig, Germany.

Received: 2 June 2020 Accepted: 4 October 2020

Published online: 19 October 2020

\section{References}

1. BMUB, 2017. Greenhouse-gas neutral Germany 2050: The Climate Action Plan 2050. https://www.bmub.bund.de/en/topics/climate-energy/clima te/national-climate-policy/greenhouse-gas-neutral-germany-2050/. Accessed 2 Nov 2017

2. BMWl, 2017. Erneuerbare Energien in Zahlen: Nationale und internationale Entwicklung im Jahr 2016. BMWI, 80 pp. https://www.bmwi.de/Redak tion/DE/Publikationen/Energie/erneuerbare-energien-in-zahlen-2016. pdf?_blob=publicationFile\&v=10. Accessed 2 Nov 2017

3. M Scheftelowitz R Becker D Thrän 2018 Improved power provision from biomass: a retrospective on the impacts of German energy policy Biomass Bioenerg 111112 https://doi.org/10.1016/j.biombioe.2018.01.010

4. Daniel-Gromke J, Rensberg N, Denysenko V, Trommler M, ReinholzT, Völler K, Beil M, Beyrich W (2017) Anlagenbestand Biogas und Biomethan: Biogaserzeugung und -nutzung in Deutschland. (DBFZ-Report, 30). Leipzig: DBFZ. X, 75 S. ISBN: 978-3-946629-24-5

5. Thrän 2019 Governance of Sustainability in the German biogas sector - Adaptive Management of the Renewable Energy Act between Agriculture and the Energy Sector Sustainability and Society Energy

6. N Scarlat J-F Dallemand F Fahl 2018 Biogas: Developments and perspectives in Europe Renew Energy 129457472 https://doi.org/10.1016/j. renene.2018.03.006

7. THorschig E Billig S Majer D Thrän 2019 Biomethane: local energy carrier or european commodity?: Opportunities and conflicts Eur Dimen Germany's Energy Trans https://doi.org/10.1007/978-3-030-03374-3_31

8. T Horschig PWR Adams M Röder P Thornley D Thrän 2016 Reasonable potential for GHG savings by anaerobic biomethane in Germany and UK derived from economic and ecological analyses Appl Energy 184840852 https://doi.org/10.1016/j.apenergy.2016.07.098

9. S Majer D Thrän 2015 Biomass Resources and Sustainability Issues for a Flexible Bioenergy Provision D Thrän Eds Smart Bioenergy Springer International Publishing Cham 3348

10. K Oehmichen D Thrän 2017 Fostering renewable energy provision from manure in Germany - where to implement GHG emission reduction incentives Energy Policy 110471477 https://doi.org/10.1016/j.enpol .2017.08.014

11. Global Bioenergy Partnership 2011 The global bioenergy partnership sustainability indicators for bioenergy 1 FAO Climate, Energy and Tenure Division, Rome, Italy

12. Herbes C, Jirka E, Braun J, Pukall K (2014a) Warum haben Mais und Biogas keinen guten Ruf? mais 41

13. Herbes C, Pustišek A, McKenna R, Balussou D (2014b) Überraschende Diskrepanz bei Biogas: lokal akzeptiert, global umstritten. Energiewirtschaftliche Tagesfragen 64

14. P Glavič R Lukman 2007 Review of sustainability terms and their definitions J Clean Prod 151818751885 https://doi.org/10.1016/j.jclep ro.2006.12.006

15. Becker, C. U., 2012. Sustainability Ethics and Sustainability Research. Springer. Chapter 2: Meaning of Sustainability, 9-15. ISBN 978-94-007-2285-9.

16. Hisschemöller, M., Tol, R. S. J., Vellinga, P., 2001. The relevance of participatory approaches in integrated environmental assessment. Integrated Assessment 2. 57-72. Kluwer Academic Publishers. 
17. S Bourdin 2019 Understanding the problems of biogas production deployment in different regions: territorial governance matters too $\mathrm{J}$ Environ Planning Manage 63916551673

18. J Mielke HVermaßen S Ellenbeck B Fernandez Milan C Jaeger 2016 Stakeholder involvement in sustainability science-A critical view Energy Res Soc Sci 177181 https://doi.org/10.1016/j.erss.2016.04.001

19. M Welp A LaVega-Leinert S Stoll-Kleemann CC Jaeger 2006 Sciencebased stakeholder dialogues: theories and tools Global Environ Change 16170181 https://doi.org/10.1016/j.gloenvcha.2005.12.002

20. K Bäckstrand 2016 Democratizing Global Environmental Governance?: Stakeholder Democracy after the World Summit on Sustainable Development Eur J Int Relat 12467498 https://doi.org/10.1177/1354066106 069321

21. O Renn P-J Schweizer 2009 Inclusive risk governance: Concepts and application to environmental policy making Env Pol Gov 19174185 https://doi.org/10.1002/eet.507

22. S Huttunen K Manninen P Leskinen 2014 Combining biogas LCA reviews with stakeholder interviews to analyse life cycle impacts at a practical level J Clean Prod 80516 https://doi.org/10.1016/j.jclepro.2014.05.081

23. KH Zemo M Termansen 2018 Farmers' willingness to participate in collective biogas investment: a discrete choice experiment study Resource Energy Econ 5287101 https://doi.org/10.1016/j.reseneeco.2017.12.001

24. E Shafiei H Stefansson El Asgeirsson B Davidsdottir M Raberto 2013 Integrated agent-based and system dynamics modelling for simulation of sustainable mobility Transp Rev 334470 https://doi.org/10.1080/01441 647.2012.745632

25. RE Freeman 1984 Strategic management: A stakeholder approach Pitman, Boston Mass. 276

26. MS Reed A Graves N Dandy H Posthumus K Hubacek J Morris C Prell CH Quinn LC Stringer 2009 Who's in and why? A typology of stakeholder analysis methods for natural resource management J Environ Manage 90 19331949
27. MS Reed 2008 Stakeholder participation for environmental management: a literature review Biol Cons 14124172431 https://doi.org/10.1016/j. biocon.2008.07.014

28. IEA Bioenergy (2019) Measuring, governing and gaining support for sustainable bioenergy supply chains, https://itp-sustainable.ieabioener gy.com/iea-publications/

29. Fachagentur Nachwachsende Rohstoffe, FNR: Bioenergiedörfer. https ://bioenergiedorffnr.de/Firmenliste Fachverband Biogas. https://www. biogas.org/edcom/webfvb.nsf/id/de alle firmen_sortiert_nach_firma

30. Biogasanlagen versus Anwohner: https://biogasanlagen-versus-anwoh ner.de/.

31. A Pehlken K Madena C Aden T Klenke 2015 Forming stakeholder alliances to unlock alternative and unused biomass potentials in bioenergy regions J Clean Prod https://doi.org/10.1016/j.jclepro.2015.05.052

32. P Sinclair B Cohen Y Hansen L Basson R Clift 2015 Stakeholder engagement within the sustainability assessment of bioenergy: case studies in heat, power and perennial and annual crops from the UK Biomass Bioenerg 731122 https://doi.org/10.1016/j.biombioe.2014.11.017

33. https://www.bmbf.de/files/neue\%20nationale\%20bio\%c3\%b6konomies trategie.pdf

34. Runsten, L., Tapio-Bistrom, M.-L., 2011. Land tenure, climate change mitigation and agriculture. Food and Agriculture Organization of the United Nations. https://www.fao.org/climatechange/30353-0c11859e8b0cac7 aabe39520498b2df22.pdf

\section{Publisher's Note}

Springer Nature remains neutral with regard to jurisdictional claims in published maps and institutional affiliations.
Ready to submit your research? Choose BMC and benefit from:

- fast, convenient online submission

- thorough peer review by experienced researchers in your field

- rapid publication on acceptance

- support for research data, including large and complex data types

- gold Open Access which fosters wider collaboration and increased citations

- maximum visibility for your research: over $100 \mathrm{M}$ website views per year

At $\mathrm{BMC}$, research is always in progress.

Learn more biomedcentral.com/submissions 